\title{
Caracterização do sistema pesqueiro da praia de Bitupitá, Litoral Extremo Oeste do Ceará: para além dos modelos teóricos
}

\author{
Characterization of the fishing system of Bitupitá beach, Extreme West Coast of Ceará: beyond \\ the theoretical models
}

Emerson Alves Arruda ${ }^{1}$

\begin{abstract}
Resumo
Este artigo apresenta uma classificação do sistema de pesca praticado na praia de Bitupitá, Litoral Extremo Oeste do Ceará, entre o que é definido pela lei federal no 11.959/2009 como pesca artesanal e pesca industrial, o entendimento de Maldonado (1986) sobre a pesca artesanal e industrial e a classificação de Diegues (2004) que divide a pesca em Pesca de Subsistência, Pesca Realizada dentro dos Moldes de Pequena Produção Mercantil e Pesca Empresarial-Capitalista. Para tanto, utilizou-se da técnica da observação participante, presente na metodologia do Diagnóstico Rural Participativo. Os resultados mostraram que o sistema de organização da pesca praticada em Bitupitá possui uma organização peculiar, com características tanto da pesca artesanal como da pesca industrial. O modelo mais próximo da realidade existente em Bitupitá é o que Diegues (2004) chama de Pequena Produção Mercantil Pesqueira (Ampliada). Conclui-se que o modelo de classificação adotado pelo Estado está longe de abranger a realidade da pesca local, pois desconsidera a complexidade das relações de produção da pequena pesca.
\end{abstract}

Palavras-chave: Pesca. Observação Participante. Comunidades Tradicionais.

\begin{abstract}
This paper shows a classification of the fishing system practiced at Bitupita beach, on the extreme west coast of Ceará, among what is defined by federal law no. 11.959/2009 as artisanal fishing and industrial fishing, Maldonado's (1986) comprehension of artisanal and industrial fishing and Diegues' (2004) classification that divides fishing into subsistence fishing, fishing carried out within the molds of small commercial production and business-capitalist fishing

To this end, we use the participant observation, a technique present in Participatory Rural Appraisal. The results showed that the fishing organization system practiced in Bitupitá has a peculiar organization, with characteristics of both artisanal and industrial fishing. The most similar model to the one existing in Bitupitá is what Diegues (2004) calls the Small Commercial Fishing Production (Expanded). It is concluded that the classification model adopted by the State does not cover the reality of local fishing, as it disregards the complexity of the production relations of small-scale fisheries.
\end{abstract}

Keywords: Fishing. Participant Observation. Traditional Communities.

\section{Introdução}

A humanidade tem uma longa e nem sempre fácil relação com o mar. Inicialmente como provedora de alimentos e segurança, posteriormente como região privilegiada para o

\footnotetext{
${ }^{1}$ Professor efetivo da Secretaria da Educação do Ceará (SEDUC-CE) e Mestrando do Programa de Pós-graduação em Geografia da Universidade Federal do Ceará (UFC). E-mail: arruda.ea@gmail.com
} 
desenvolvimento industrial e comercial, a zona costeira passou a ser vista também como espaço de grande importância para o lazer e a conservação (CARTER, 2002). Historicamente, as áreas litorâneas registram um claro fenômeno de concentração demográfica em quase todo o mundo, em que as aglomerações costeiras exercem um importante papel na articulação da hinterlândia com a economia-mundo (MORAES, 2007).

Este papel de articuladora entre as áreas interiores e o circuito externo da economia elevava os sítios portuários litorâneos brasileiros a uma situação de vantagem frente às aglomerações interiores na época colonial. As primeiras redes de cidades brasileiras se formaram a partir da aglomeração em torno dos portos que serviam aos circuitos de produção mais importantes (MORAES, 2007).

Além de encerrar as grandes aglomerações urbanas oriundas do processo de colonização portuguesa, o litoral brasileiro também é o lócus de reprodução de inúmeras comunidades tradicionais, como os quilombolas, os indígenas e as comunidades pesqueiras.

O extrativismo, com destaque para a pesca artesanal, constitui-se em importante fonte de renda para a população da zona costeira cearense. Essa atividade, que tem importância fundamental para diversos municípios do litoral cearense, contribui com a produção de pescado que circula no mercado interno além de ser a grande responsável pelo nascimento e sobrevivência de muitas comunidades pesqueiras (RODRIGUES; GIUDICE, 2011). De acordo com a lei federal n. 11.959, de 29 de junho de 2009, esse modelo de pesca caracteriza-se pela atuação próxima à costa, baseada na simplicidade onde os próprios trabalhadores desenvolvem suas artes e instrumentos, auxiliados ou não por pequenas embarcações.

Cardoso (2001) alerta que a questão conceitual sobre a pesca artesanal é bastante ampla e se baseia em Diegues $(1983,1988)$ para caracterizar essa atividade. No âmbito dessa discussão, objetivamos caracterizar a pesca artesanal praticada em Bitupitá, litoral extremo oeste do Ceará, para demonstrar que algumas características da pesca industrial podem estar presentes na pequena pesca, indicando as diferentes escalas e relações sociais de produção que a pesca artesanal pode alcançar.

Segundo Diegues $(1983,2004)$, a pesca realizada dentro dos moldes de pequena produção mercantil se subdivide em duas categorias: a dos pescadores-lavradores e a dos pescadores artesanais. Para os pescadores-lavradores, a pesca corresponde a uma atividade complementar, que utiliza embarcações não motorizadas, com limitado raio de ação, e petrechos fixos, como o curral.

A pesca artesanal, de acordo com Diegues (1983), encontra-se em um contexto de pequena produção mercantil ampliada, caracterizada, entre outros aspectos, pela baixa capacidade de acumulação - o que torna o pescador altamente dependente dos atravessadores, devido à elevada perecibilidade do seu produto - e pela produção de um excedente reduzido e irregular. 
O mercado é o objetivo central do pescador artesanal, "ainda que o balaio ou cesto de peixe, religiosamente separado antes da partilha, constitua uma das bases de sua sobrevivência e de sua família” (DIEGUES, 1983, p. 155). A valorização comercial dos recursos pesqueiros pode, portanto, ampliar o poder de predação das técnicas artesanais (DIEGUES, 1983), ocasionando diversos problemas socioeconômicos e ambientais para as comunidades pesqueiras.

Os currais são petrechos fixos dispostos em linha perpendicular à costa, confeccionados com telas de arame galvanizado e madeira (Figura 1) comuns em quase toda a costa cearense (SERAINE, 1958 apud. PAIVA; NOMURA, 1965; TAMAR-ICMBIO, 2013).

\section{FIGURA 1: ESTRUTURAS QUE COMPÕEM UM CURRAL}

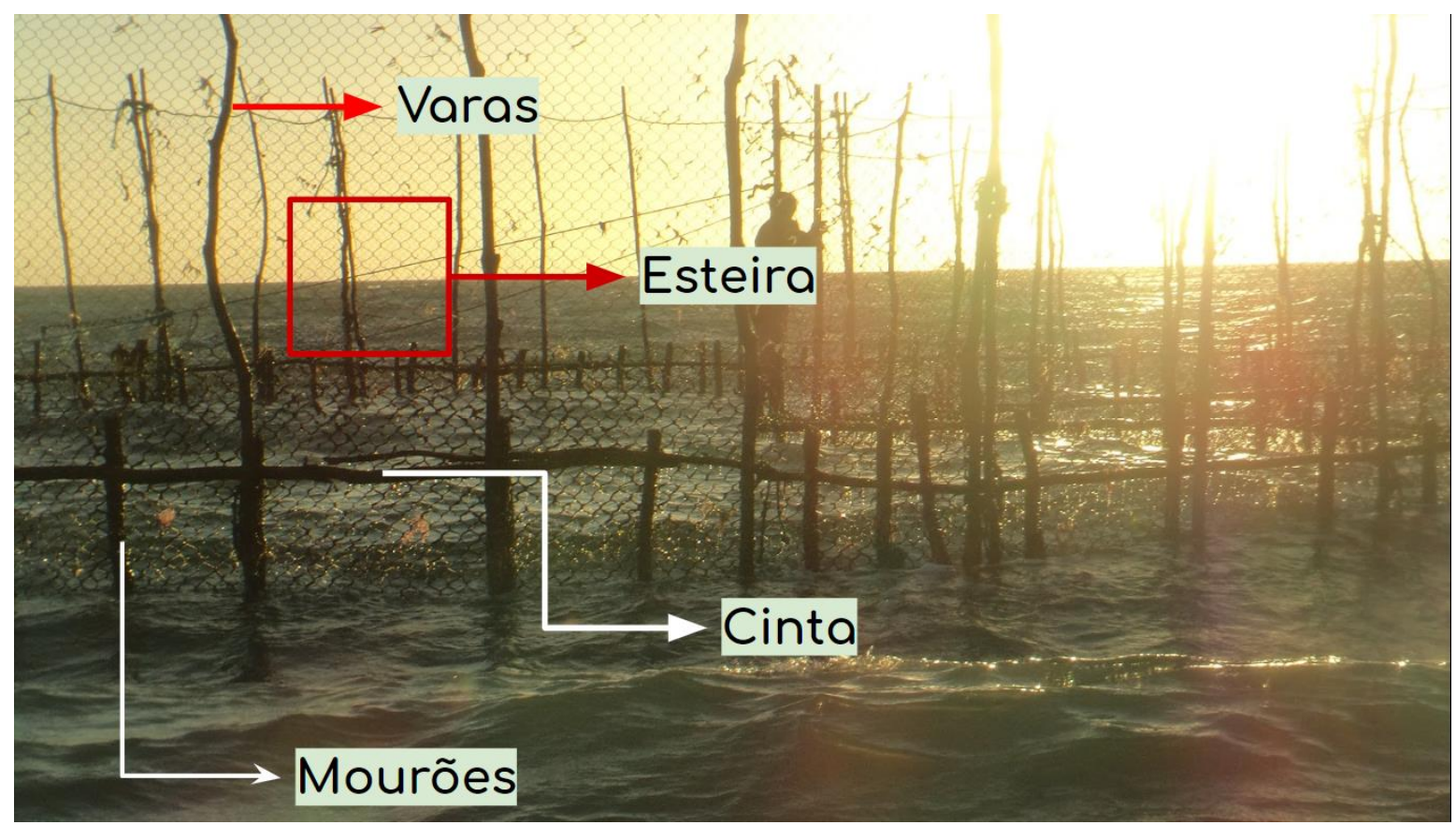

FONTE: Elaborado pelo autor; foto do autor.

Essas armadilhas são compostas por quatro compartimentos: a espia, a sala grande, a salinha e o chiqueiro (Figura 2). A espia consiste em uma estrutura formada por um conjunto de madeiras enfileiradas que direciona o cardume para o interior do curral; a sala grande é o local para onde o peixe vai ao tentar desviar da espia; a salinha é estrutura semelhante à sala grande, de onde o peixe não consegue escapar e vai para o chiqueiro (estrutura em formato circular onde é feita a despesca). 


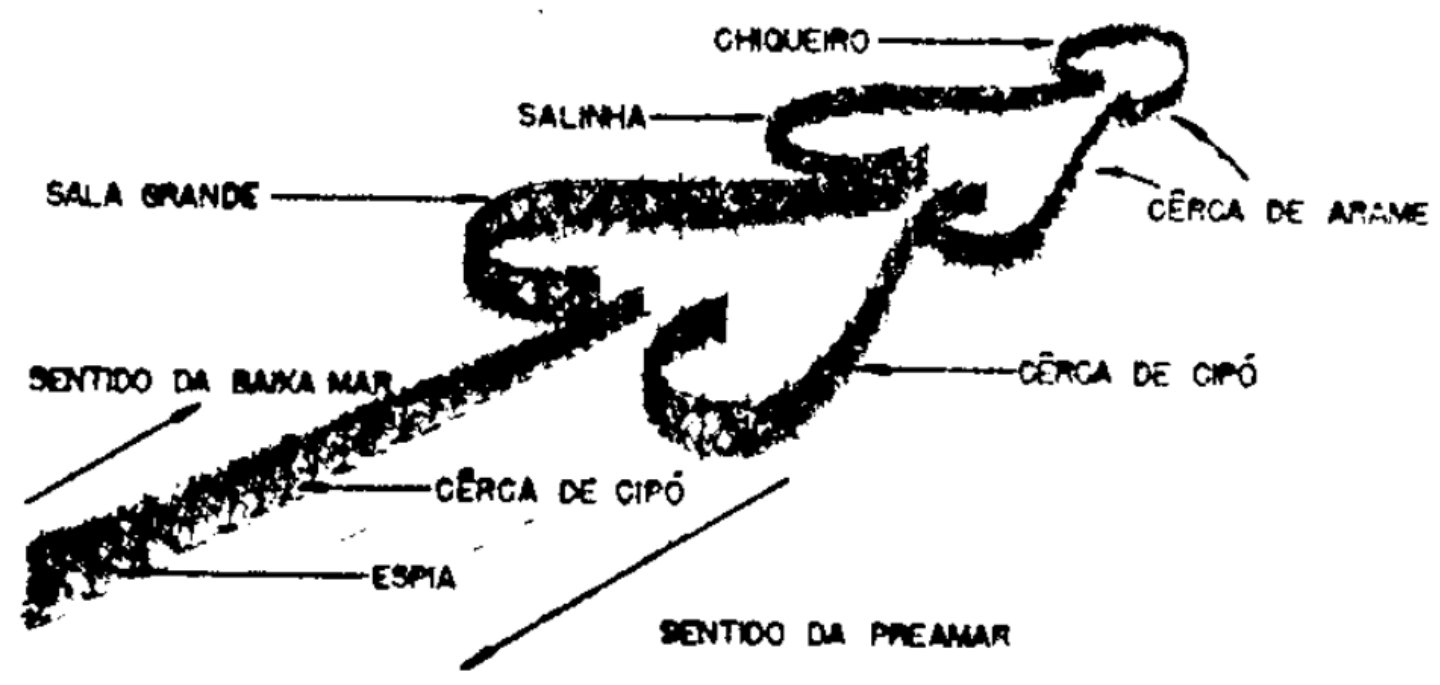

FONTE: Paiva; Nomura (1965)

Os currais não dispõem de nenhum tipo de atrativo que leve os peixes ao seu interior. Sua instalação, portanto, requer um profundo conhecimento e uma apurada observação da movimentação das correntes marítimas locais. Somente os pescadores mais experientes conseguem indicar os locais mais adequados para a instalação desse tipo de petrecho. Eles observam o sentido das correntes através de mergulhos e técnicas próprias para indicar o ponto mais apropriado para o curral. Ao nadar de acordo com a corrente, os cardumes esbarram na espia e vão em direção ao interior dessa arte de pesca, onde ficam retidos.

A despesca dessas armadilhas é realizada por três a dez pescadores, dependendo do tamanho e profundidade do curral, sempre na maré baixa. Os vaqueiros, como são conhecidos os trabalhadores responsáveis pela despesca, passam uma rede de cerco no chiqueiro uma ou duas vezes e embarcam o pescado na canoa (Figura 3), onde é feita a separação das "paias" de cada pescador e a separação do excedente para a comercialização. 


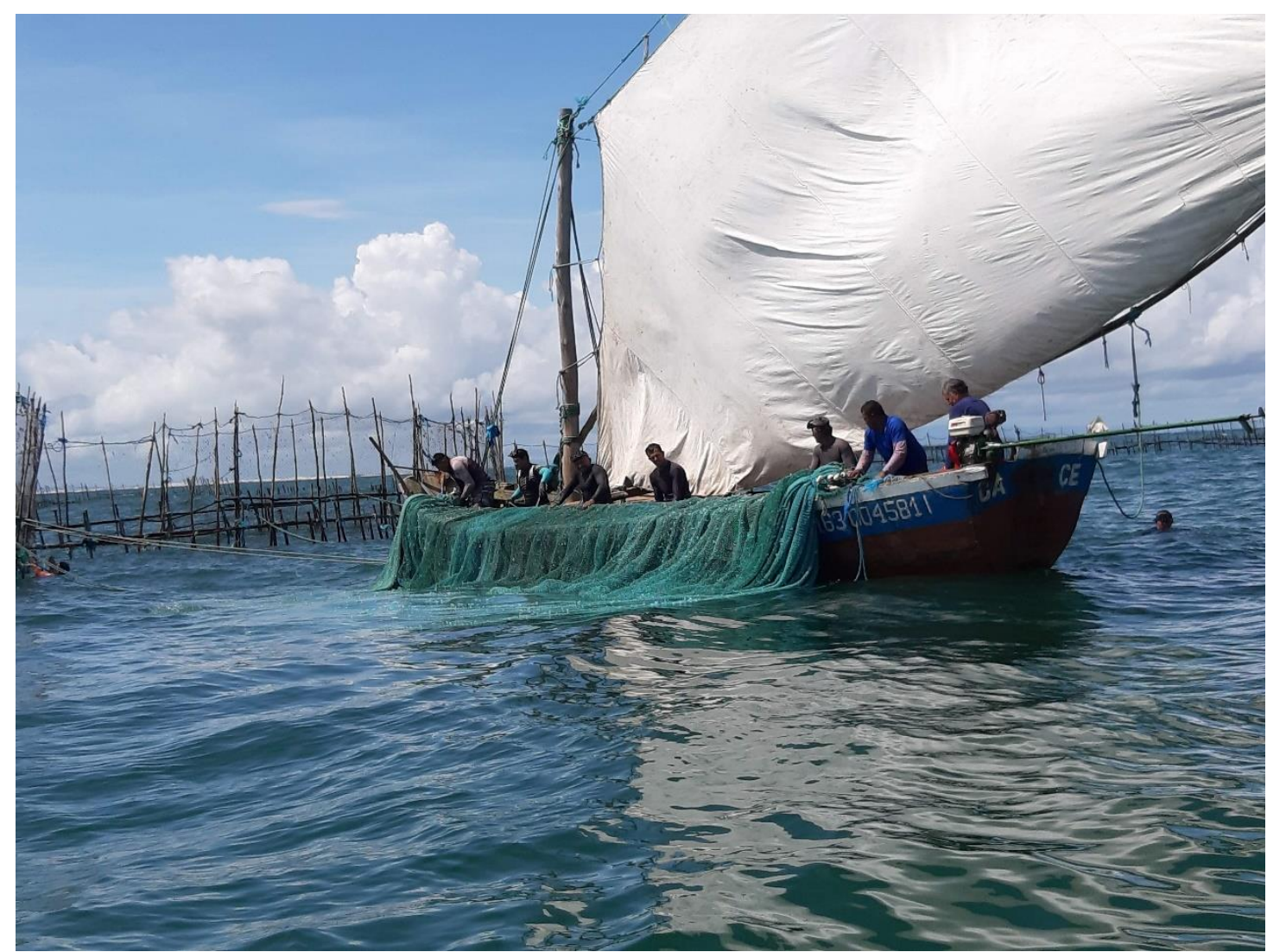

FONTE: Fotografia do autor (2019)

Em Bitupitá, distrito do município de Barroquinha, no litoral extremo oeste do Ceará, a pesca de curral é uma atividade que se destaca. Dados coletados em campo registraram que Bitupitá chegou a ter mais de 70 currais em pleno funcionamento na década de 1960. Em 2019, foram mapeados 42 currais no mar de Bitupitá, nos quais trabalham cerca de 250 pescadores. Embora Diegues (1983, 2004) indique que o curral é um aparelho mais comumente utilizado pelos pescadores-lavradores, em Bitupitá esse petrecho é utilizado em um contexto de pequena produção mercantil ampliada carregada de marcas da relação capitalista.

O presente artigo objetiva classificar a pesca de curral com relação marco legal da pesca no Brasil (Lei n. 11.959, de 29 de junho de 2009, que dispõe sobre a Política Nacional de Desenvolvimento Sustentável da Aquicultura e da Pesca) e aos tipos de pesca descritos por autores que são referência sobre o tema da pesca: Diegues (2004) e Maldonado (1986). Buscamos, com isso, entender quais são os limites teóricos que se impõem sobre os tipos de pesca descritos pela Política Nacional de Desenvolvimento Sustentável da Aquicultura e da Pesca. Buscamos, ainda, saber se lei que regulamenta pesca no Brasil utilizou-se de modelos teóricos considerados clássicos nos estudos da pesca no Brasil. 


\section{Caracterização da área e do sistema pesqueiro dos currais de Bitupitá}

Bitupitá é um dos três distritos do município de Barroquinha, situado na mesorregião do Litoral de Camocim e Acaraú, no litoral extremo oeste do Ceará, a cerca de 440 km de distância de Fortaleza através da rodovia estadual CE-085 (Figura 4). Sua localização, posicionada entre dois destinos turísticos internacionalmente conhecidos, a praia de Jericoacoara e os Lençóis Maranhenses, pode ser considerada estratégica pelo setor turístico.

De acordo com relatos orais, o povoado se situava mais a oeste, em uma localidade conhecida como Anil, que teve seu território ocupado pelo avanço das marés. Posteriormente os moradores se mudaram mais para leste do antigo povoado de Anil, em um lugar que ficou conhecido como Almas, nome dado em alusão a um pequeno peixe muito abundante na região em momentos pretéritos conhecido localmente como "Alma de gato". O povoado das Almas também teria sido ocupado pelo avanço do mar, fato que obrigou os moradores a se deslocarem para onde estão atualmente.

\section{FIGURA 4: MAPA DE LOCALIZAÇÃO DO DISTRITO DE BITUPITÁ}

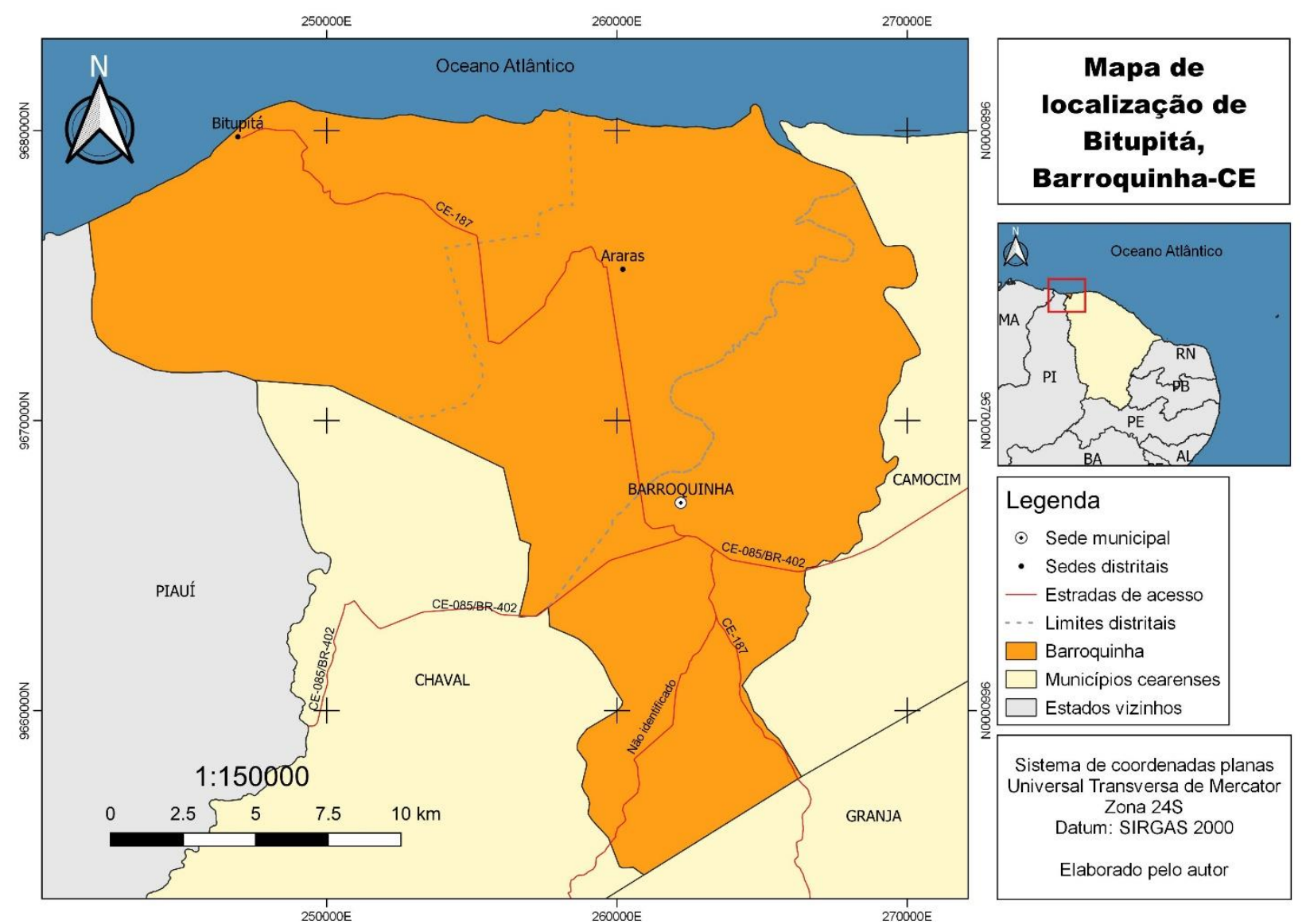

FONTE: Elaborado pelo autor. Dados: IBGE, 2019; IPECE, 2019. 
Os dados do último Censo Demográfico (2010) disponíveis no portal do Instituto Brasileiro de Geografia e Estatística (IBGE) revelaram que Barroquinha possuía 14.476 habitantes, dos quais apenas $8,5 \%$ possuíam algum tipo de ocupação. O salário médio mensal dos trabalhadores formais era de 1,5 salários mínimos em 2016, com quase $60 \%$ da população com rendimento nominal mensal per capita de até 1/2 salário mínimo. Barroquinha é um município costeiro peculiar, pois sua sede municipal não é banhada pelo mar (Figura 3), em oposição ao que acontece com a maioria dos municípios litorâneos no Brasil.

De acordo com o Decreto $\mathrm{n}^{\circ}$ 6.040, de 7 de fevereiro de 2007, as comunidades tradicionais constituem grupos que "possuem formas próprias de organização social, que ocupam e usam territórios e recursos naturais como condição para sua reprodução cultural, social, religiosa, ancestral e econômica, utilizando conhecimentos, inovações e práticas gerados e transmitidos pela tradição" (BRASIL, 2007). Bitupitá, portanto, apresenta características de comunidade tradicional, pois a pesca, transmitida de geração em geração, é, segundo os pescadores locais, uma atividade sem a qual não seria possível a reprodução econômica da comunidade.

Na classificação de Moraes (2007), o litoral dos estados setentrionais do Brasil as áreas submetidas à lógica mercantil podem ser consideradas apenas episódicas. Nesta classificação, portanto, Bitupitá enquadra-se como uma comunidade com um padrão de uso do solo assentado em atividades extrativas (destinadas ao mercado) e de autoconsumo, com a pesca ocupando um espaço de destaque na comunidade.

No mar de Bitupitá, são descritos três tipos de curral: os currais de terra (mais próximos da costa), os currais de meia carreira e os currais de fora. De acordo com o mapeamento realizado em março de 2019 (Figura 5), o curral mais distante ficava a cerca de 6,6 milhas náuticas (cerca de 12,3 km) da linha de base. Já os mais próximos ficavam a cerca de 500 metros da praia. 


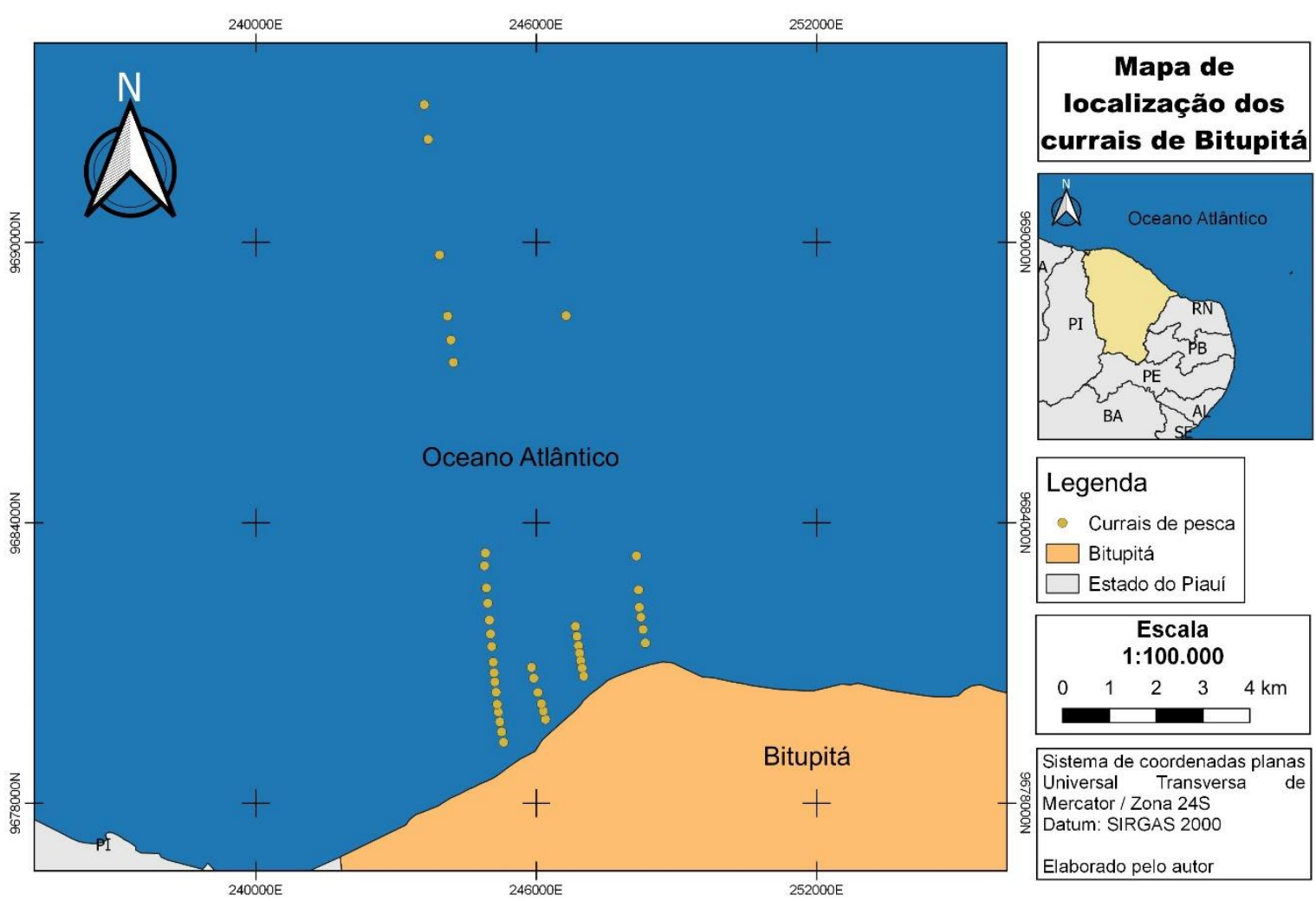

FONTE: Elaborado pelo autor (2019).

Os currais de beira e os currais de meia carreira são predominantes na região, por conta do custo menor de instalação e manutenção; os currais de fora, apesar de serem mais produtivos, são os menos utilizados, pois, como são instalados em alto mar, sua deterioração é maior, o que aumenta seu custo de manutenção.

Segundo Araújo e Rodrigues (2015) existiam apenas quatro mestres marcadores de currais em Bitupitá no ano da sua pesquisa. Pesquisa de campo realizada em 2019 mostraram que, devido ao avanço da idade, dois mestres marcadores afastaram-se das atividades relativas à pesca. Os mestres marcadores são os vaqueiros que têm maiores conhecimentos acerca do comportamento dos peixes e do movimento das correntes locais. Este saber é transmitido de geração em geração e cada mestre marcador dispõe de técnicas próprias herdadas de seus ascendentes. Para a marcar um curral, os mestres e os donos dos currais estabelecem um acordo informal, em que o mestre é remunerado apenas uma vez, sem ter participação no produto das pescarias.

Nos currais, trabalham os vaqueiros, os mata-vaqueiros e os ajudantes. Os vaqueiros são os pescadores responsáveis pela despesca. O mata-vaqueiro é quem se encarrega da canoa: trazê-la para perto da costa na hora do embarque dos companheiros, fundear quando chega ao curral e lavá-la 
periodicamente para diminuir o desgaste e remover organismos incrustantes. O papel dos ajudantes é auxiliar o embarque da rede carregada de peixes na canoa.

Nos currais mais próximos da costa trabalham de três a quatro pescadores: um mata-vaqueiro, um ou dois vaqueiros e um ajudante. Os vaqueiros e os mata-vaqueiro são trabalhadores fixos dos currais, já os ajudantes não estão, necessariamente, em todas as pescarias.

Após a despesca do curral, o pescado é vendido a atravessadores que ficam na praia à espera das canoas. A produção de um dia de pesca é dividida da seguinte forma: 5\% do apurado em dinheiro mais uma certa quantidade de peixe (a "paia" ou "boia") pertencem ao mata-vaqueiro; os vaqueiros, além do peixe, levam $25 \%$ do produto da venda; os ajudantes são remunerados apenas com peixe. Os $70 \%$ restantes do dinheiro arrecadado com a venda do peixe pertencem ao dono do curral.

O dono do curral, que não é, necessariamente, pescador, é quem compra os materiais (madeira, arame, canoa, motor etc.) e contrata a mão de obra necessária para a montagem dessa arte de pesca. Os pescadores realizam pequenas reformas nos currais, mas os outros trabalhos, como tecer as esteiras e as redes e fazer o "amouroamento" (fixar os mourões danificados pelo efeito da água salgada, do vento, das ondas etc.), são realizados por pessoas externas ao grupo responsável pela despesca do curral.

\section{Metodologia}

Para a caracterização da pesca de curral dispomos da técnica indicada pelo Diagnóstico Rural Participativo conhecida como observação participante. A observação participante é uma ferramenta indicada para a primeira fase da pesquisa e visa criar laços de confiança para compartilhar tempo com os comunitários (VERDEJO, 2010). Segundo Maldonado (1986), o contato com o mar - um elemento natural arriscado e imprevisível - e os reveses sofridos no mercado decorrentes da exploração e ganância dos atravessadores e da alta perecibilidade da produção fazem do pescador um sujeito hesitante e, por vezes, arredio. A conquista da credibilidade junto a pescadores é um fator primordial para o bom andamento do trabalho, pois, conforme Verdejo (2010, p.28), é fundamental compreender como e por que "agem desta ou de outra maneira antes de opinar e de propor 'a solução lógica"”.

Minayo (2016) considera a observação participante essencial na pesquisa qualitativa, podendo ser mais importante do que qualquer outra técnica, por ser capaz de permitir a compreensão da realidade tal como ela é. Ainda segundo Minayo (2016, p.64), a observação participante necessariamente, prisioneiro de um instrumento rígido de coleta de dados ou de 
hipóteses testada antes ou durante o processo de pesquisa. Na medida em que convive com o grupo, o observador pode retirar do seu roteiro questões que percebe serem irrelevantes do ponto de vista dos interlocutores; consegue também compreender aspectos que vão aflorando aos poucos, situação impossível para um pesquisador que trabalha com questionários fechados $\mathrm{e}$ antecipadamente padronizados.

Os trabalhos de campo ocorreram em dezembro de 2018 e março de 2019, oportunidade em que se estabeleceram os primeiros contatos com pescadores, marcadores de currais, dirigentes da colônia Z-23 e com o titular da Secretaria de Turismo, Meio Ambiente, Desenvolvimento Rural e Pesca do município de Barroquinha-CE. Foram, ainda, realizados embarques junto aos pescadores para o acompanhamento do processo de despesca dos currais e venda do pescado na praia.

Spradley (1980 apud. Flick, 2009) distingue três fases da observação participante: observação descritiva - utilizada no início da pesquisa para apreender, o máximo possível, a complexidade do campo, fornecendo descrições não-específicas ao pesquisador e uma orientação para o tema em estudo; observação focalizada - limita a análise do pesquisador aos processos e problemas mais essenciais para a questão da pesquisa; observação seletiva - ocorre já na fase final da coleta de dados e concentra-se em encontrar mais indícios e exemplos para os tipos de práticas e processos descobertos na segunda etapa.

Durante a fase da observação descritiva, puderam ser observados aspectos como a divisão dos ganhos após a despesca do curral, a organização hierárquica e os vínculos entre os pescadores e os donos dos currais e a forma como é comercializada a produção. Além disso, investigamos os custos e a origem dos materiais para a montagem dos currais, com base em entrevistas não estruturadas com cinco donos de currais.

A escolha das entrevistas não estruturadas relaciona-se com a fase da observação descritiva. Segundo Flick (2009), o uso de fichas estruturadas durante a fase descritiva pode fazer com que o observador deixe passar certos aspectos que não estejam presentes nas fichas. Desta forma, "a observação descritiva deve abster-se de utilizar fichas estruturadas de forma muito severa a fim de evitar que a atenção do observador fique restrita e que sua sensibilidade esteja limitada ao novo" (FLICK, 2009, p. 208).

Para o trabalho de georreferenciamento dos currais, foi utilizado um aparelho receptor de GPS da marca Garmin, linha Etrex, modelo H. Como o aparelho era operado em mar aberto, com pouca cobertura de nuvens, a precisão registrada ficava em torno de 3 metros. $\mathrm{O}$ aparelho foi configurado para o datum WGS84. Foi utilizada também uma canoa equipada com motor de rabeta da marca Honda modelo GX390QH para navegar até os currais, que chegava aproximadamente a um metro de cada local de coleta dos pontos. 
Os pontos foram marcados no local mais próximo do fundo do chiqueiro, resultando nas coordenadas presentes na Tabela 1. Os dados foram salvos no software Excel ${ }^{\circledR}$ em formato .csv e depois foram exportados para o software QGis a fim de criar um mapa de localização dos currais ativos em Bitupitá (Figura 5).

TABELA 1: COORDENADAS DOS CURRAIS DE BITUPITÁ

\begin{tabular}{|c|c|c|}
\hline Ponto & Coordenada Este & Coordenada Norte \\
\hline 1 & 243603 & 9692944 \\
\hline 2 & 243687 & 9692204 \\
\hline 3 & 243932 & 9689730 \\
\hline 4 & 244105 & 9688422 \\
\hline 5 & 244174 & 9687910 \\
\hline 6 & 244228 & 9687430 \\
\hline 7 & 244892 & 9683080 \\
\hline 8 & 244913 & 9683350 \\
\hline 9 & 244934 & 9682604 \\
\hline 10 & 244962 & 9682276 \\
\hline 11 & 244998 & 9681916 \\
\hline 12 & 245023 & 9681618 \\
\hline 13 & 245049 & 9681352 \\
\hline 14 & 245079 & 9681016 \\
\hline 15 & 245098 & 9680790 \\
\hline 16 & 245115 & 9680594 \\
\hline 17 & 245142 & 9680372 \\
\hline 18 & 245165 & 9680116 \\
\hline 19 & 245189 & 9679952 \\
\hline 20 & 245221 & 9679738 \\
\hline 21 & 245261 & 9679524 \\
\hline 22 & 245301 & 9679302 \\
\hline 23 & 245899 & 9680906 \\
\hline 24 & 245948 & 9680672 \\
\hline 25 & 246035 & 9680366 \\
\hline 26 & 246112 & 9680128 \\
\hline 27 & 246151 & 9679970 \\
\hline 28 & 246198 & 9679792 \\
\hline 29 & 246640 & 9688430 \\
\hline 30 & 246841 & 9681782 \\
\hline 31 & 246872 & 9681568 \\
\hline 32 & 246906 & 9681368 \\
\hline 33 & 246928 & 9681208 \\
\hline 34 & 246953 & 9681046 \\
\hline 35 & 246982 & 9680890 \\
\hline
\end{tabular}




\begin{tabular}{l|l|l}
\hline 36 & 247017 & 9680714 \\
\hline 37 & 248147 & 9683290 \\
\hline 38 & 248190 & 9682562 \\
\hline 39 & 248207 & 9682192 \\
\hline 40 & 248240 & 9681976 \\
\hline 41 & 248285 & 9681716 \\
\hline 42 & 248335 & 9681426 \\
\hline
\end{tabular}

FONTE: Elaborada pelo autor.

\section{A pesca de curral: entre $o$ artesanal e o industrial}

A observação participante insere-se no conjunto das metodologias denominadas qualitativas, sendo utilizada durante a fase exploratória da pesquisa. Consiste na inserção e participação do pesquisador no cotidiano da comunidade estudada (VERDEJO, 2010). A interação entre o pesquisador e o pesquisado é um fator de primordial para adquirir confiança e obter informações. Durante as visitas feitas à comunidade no decorrer da fase da observação descritiva, as análises feitas e o convívio com a comunidade possibilitaram elencar alguns caracteres que inserem a pesca de curral num interstício entre a pesca artesanal e a pesca industrial.

\section{Classificação da pesca de curral de acordo com a Política Nacional de Desenvolvimento} Sustentável da Aquicultura e da Pesca (Lei no 11.959, de 29 de junho de 2009)

$\mathrm{O}$ artigo $8^{\circ}$ da lei federal $\mathrm{n}^{\circ} 11.959$, de 29 de junho de 2009, classifica a pesca comercial em dois tipos: artesanal e industrial. Segundo a lei citada, a pesca artesanal é "praticada diretamente por pescador profissional, de forma autônoma ou em regime de economia familiar, com meios de produção próprios ou mediante contrato de parceria, desembarcado, podendo utilizar embarcações de pequeno porte" (BRASIL, 2009). Já a pesca industrial caracteriza-se por ser "praticada por pessoa física ou jurídica e envolver pescadores profissionais, empregados ou em regime de parceria por cotas-partes, utilizando embarcações de pequeno, médio ou grande porte, com finalidade comercial" (BRASIL, 2009).

Considerando a classificação presente na Política Nacional de Desenvolvimento Sustentável da Aquicultura e da Pesca (Lei $n^{\circ} 11.959$, de 29 de junho de 2009), a pesca praticada majoritariamente em Bitupitá não se classifica em nenhum dos dois tipos. Não pode ser considerada artesanal, pois a mão de obra utilizada nem sempre é familiar. Muitas vezes, o dono do curral não é sequer pescador e os trabalhadores de um mesmo curral não são, necessariamente, da mesma família, ou seja, há uma separação entre o proprietário dos meios de produção (curral, canoa, motor) e os trabalhadores 
(vaqueiros, mata-vaqueiros e ajudantes). De acordo com Diegues (1983), à medida que a pesca deixa de ser uma atividade de complemento da renda para se tornar a principal fonte de recursos, o grupo doméstico passa a perder importância, pois esta atividade passa a exigir conhecimentos mais específicos.

De acordo com os dados disponibilizados pela Colônia Z-23 de Bitupitá, em 2015 havia 338 sócios ativos, sendo 209 homens e 129 mulheres e 143 embarcações licenciadas. Nos levantamentos de campo, registramos em torno de 250 pescadores que trabalham nos 42 currais presentes na região. Além desses 250 existem outros pescadores que trabalham na pesca de linha e de lagosta e os catadores de caranguejo e marisco. Como cada curral possui apenas uma embarcação, inferimos que muitos pescadores de Bitupitá não possuem registro de pescador profissional. Portanto, a pesca de curral também não pode ser considerada industrial, pois, de acordo com o artigo $2^{\circ}$ dessa mesma lei, o pescador profissional dever ser licenciado pelo órgão público competente.

\section{Classificação da pesca de curral de acordo Maldonado (1986)}

De acordo com Maldonado (1986, p. 15), o pescador artesanal "se caracteriza pela simplicidade da tecnologia e pelo baixo custo da produção [...], produzindo com grupos de trabalho formado por referenciais de parentesco, sem vínculo empregatício entre as tripulações e os mestres dos botes". Outra característica importante do pescador artesanal, segundo a mesma autora, é a necessidade de intermediários para comercializar o seu produto, pois não dispõem de infraestrutura para a conservação nem de meios para transportá-lo aos mercados mais distantes.

$\mathrm{Na}$ pesca industrial, as três atividades básicas - captura, industrialização e comercialização do pescado - são desenvolvidas separadamente, e as tarefas pertinentes a elas, desempenhadas por grupos de trabalho diferenciado.

O pescador assalariado participa apenas da captura do pescado, sem tomar qualquer decisão, seja sobre a constituição das equipes de trabalho, seja sobre a escolha das rotas de pesca e duração da jornada desta. (MALDONADO, 1986, p. 16)

Maldonado (1986) afirma que, em todo o mundo, a pesca artesanal contrasta com a industrial. Mais a diante a autora faz uma ressalva, assinalando que não convém tomar a pesca industrial e a artesanal como "compartimentos estanques". Segundo a autora, "os estudos sobre a organização econômica da pesca têm revelado a coexistência de unidades de produção de características capitalistas e outras de estrutura e operação artesanais, que são consideradas, em alguns contextos, como pré-capitalistas" (p. 28).

A pesca de curral desenvolvida em Bitupitá corresponde a um sistema artesanal com fortes características industriais: há uma diferenciação entre os donos dos meios de produção (dono do curral e dos demais instrumentos de pesca) e os trabalhadores dos currais, tanto no que se refere à 
divisão dos lucros quanto à especialização dos trabalhos para a montagem dessas armadilhas. Apesar de utilizarem uma tecnologia relativamente simples, o custo de produção não é baixo. Um dos mestres marcadores de currais da região relatou que para montar um curral de terra são necessários cerca de $1.500 \mathrm{~kg}$ de arame para a tela, que custa em torno de $\mathrm{R} \$ 10,00 / \mathrm{kg}$, e mais 750 "pau" (mourões e varas), o que vai fazer com que o dono do curral gaste mais de $\mathrm{R} \$ 20.000,00$. Um curral de meia carreira custa em torno de $\mathrm{R} \$ 50.000,00$ (cinquenta mil reais) e um curral de fora não sai por menos de $\mathrm{R} \$ 100.000,00$ (cem mil reais). Devido ao desgaste do material, todos os anos os currais "caem", ou seja, se deterioram, ficando impossibilitados de capturarem os peixes. Então é necessário "levantar o curral”, o que significa que as madeiras e a tela devem ser substituídas por outras. A duração média desses materiais é em torno de 10 meses.

O trabalho familiar é comum nos currais de terra, onde o pescador é o dono do curral e os membros da família ajudam na pescaria. Nos currais maiores, o dono, apesar de não trabalhar na pesca, estabelece a hierarquia entre os pescadores, que nem sempre possuem laços de parentesco. Os trabalhadores dos currais são divididos em vaqueiro, mata-vaqueiro e ajudante. Entre os vaqueiros, um exerce a função de encarregado, que tem a tarefa de vender a produção quando chega da pescaria.

O pagamento dos trabalhadores é feito da seguinte maneira: os vaqueiros tomam parte de $25 \%$ do apurado mais uma pequena quantidade de peixe (a "paia" ou "boia") que pode ser consumido ou vendido. O mata-vaqueiro tem direito a $5 \%$ da renda mais a sua "paia" de peixe. O ajudante não tem direito a nenhuma porcentagem da produção, apenas à sua "boia".

Os intermediários têm grande capacidade de interferir economicamente na pesca, definindo, inclusive, o preço pelo qual o pescado será comprado. O pescador, portanto, não tem poder de decidir sobre a comercialização do pescado ou sobre a composição das equipes de trabalho, característica marcadamente de pescarias industriais, de acordo com Maldonado (1986).

\section{Classificação da pesca de curral de acordo com Diegues (2004)}

Em seu livro A pesca construindo sociedades, publicado em 2004, Antonio Carlos Diegues classifica as formas de produção existentes ao longo do litoral brasileiro em três categorias: a) a Pesca de Subsistência; b) a Pesca Realizada dentro dos Moldes de Pequena Produção Mercantil, que se subdivide em Produção Mercantil Simples dos Pequenos Produtores Litorâneos e Pequena Produção Mercantil Pesqueira (Ampliada) e; c) a Pesca Empresarial-Capitalista.

Não podemos classificar o principal tipo de pesca praticado em Bitupitá como de subsistência, pois a finalidade da produção é fundamentalmente comercial.

Segundo o autor, o curral é um petrecho típico da Produção Mercantil Simples dos Pequenos Produtores Litorâneos. Esse tipo de produção se caracteriza por constituir uma atividade 
complementar, inserida em um contexto de "atividades predominantemente agrícolas que constituem a base de subsistência e organização social desses pescadores” (DIEGUES, 2004, p. 134). As unidades de trabalho são constituídas pelos membros da família, seja no trato da terra, seja na captura do pescado, que pode ser salgado e secado para o consumo direto ou vendido, "constituindo uma das principais fontes de dinheiro disponível para a compra de outras mercadorias essenciais" (DIEGUES, 2004, p. 134).

A Produção Mercantil Simples dos Pequenos Produtores Litorâneos ainda é caracterizada por uma incipiente divisão do trabalho, pois, em geral, as mulheres não participam da captura dos peixes; pelo igualitarismo na divisão do produto; uso de embarcações não motorizadas, com raio de ação limitado, que servem muito mais como meio de transporte do que como instrumento de pesca. Os aparelhos fixos de captura são os instrumentos privilegiados desse tipo de produção, pois o agricultor não tem conhecimentos nem experiência para ir buscar o peixe, são os peixes que "acostam".

A pesca realizada em Bitupitá se assemelha mais ao que Diegues (2004) chama de Pequena Produção Mercantil Pesqueira (Ampliada). Nesse tipo de produção a pesca deixa de ser uma atividade complementar e torna-se a principal fonte de renda. A mão de obra deixa de ser eminentemente familiar à medida que os investimentos em materiais mais eficientes demandam uma tripulação mais apropriada para capitalizar a pesca e garantir o retorno financeiro das aquisições realizadas. Outro aspecto importante dessa modalidade de produção é a disparidade na distribuição do produto. Isto por que os custos maiores na manutenção da embarcação motorizada, pagamento de financiamentos feitos e, no caso de Bitupitá, na compra de madeira e arame para substituir os materiais gastos pelo contato constante com a água salgada fazem com que o dono do curral passe a exigir uma cota maior na divisão da produção.

A pequena produção mercantil ampliada exige conhecimentos mais específicos que os usados pelo pescador-lavrador da produção mercantil simples. A propriedade dos meios de trabalho se aparta do meio familiar. Na comercialização, as firmas de compra e financiamento da produção se sobrepõem aos atravessadores individuais. Os pescadores passam a depender cada vez mais dessas firmas, que lhe financiam até a comida em momentos difíceis. É na produção ampliada que surge o pescador como tal, vivendo exclusiva ou quase exclusivamente da pesca, com a produção voltada fundamentalmente para o comércio.

A única diferença entre a pequena produção mercantil ampliada e o modelo de pesca praticado em Bitupitá é que os atravessadores individuais ainda têm um papel marcante na comercialização do pescado, chegando, frequentemente, a comprar mais de uma tonelada de pescado por curral. Somente depois de passar por esses atravessadores individuais é que a produção chega às firmas localizadas na capital ou em estados da região Norte e Nordeste. 
A pesca de curral praticada em Bitupitá tem contrastes marcantes com o modelo EmpresarialCapitalista descrito por Diegues (2004). Alguns aspectos são marcadamente diferentes entre os dois sistemas: num barco de pesca empresarial as funções são remuneradas por um salário, embora possa haver pagamento atrelado à produção; o uso de equipamentos modernos como sonar, radar e ecossonda, é comum na produção empresarial e a atividade é voltada totalmente para a produção de mercadorias. Na pesca de curral, esses equipamentos modernos são dispensáveis e, apesar da produção ser voltada fundamentalmente para o mercado, a "boia" tem uma grande importância para os trabalhadores, visto que, para uma grande parcela dos pescadores, esse é o único meio de pagamento para o seu trabalho.

\section{Conclusão}

Segundo Maldonado (1986) a pesca industrial e a artesanal possuem contrastes bem marcados, mas essa diferença não foi constatada na pesca de curral em Bitupitá, o que nos permite concluir que a pesca artesanal é dotada de diferentes relações sociais de produção de acordo com as artes de pesca utilizadas e de acordo com o capital investido pelos trabalhadores do mar. O modelo mais próximo da realidade existente em Bitupitá é o que Diegues (2004) chama de Pequena Produção Mercantil Pesqueira (Ampliada). Porém, conforme Azevedo (2012), a pesca artesanal pode revelar padrões de transição para a relação capitalista, mesmo em condições de baixo grau de tecnificação. Assim, na pesca artesanal, percebe-se "um processo de diferenciação social que é próprio da lei do valor, gerando processos transicionais para a forma capitalista" (AZEVEDO, 2012, p. 78).

A pequena pesca pode alcançar diferentes escalas e relações de produção, mas a elevada dependência dos fatores naturais, a produção de um excedente reduzido e irregular, a baixa capacidade de acumulação e a alta perecibilidade do pescado são condições limitantes ao desenvolvimento das relações capitalistas (assalariamento, propriedade privada da terra, acumulação de capital etc.). É importante, portanto, levar em consideração que a complexidade de uma realidade empírica muitas vezes não cabe em modelos teóricos, os quais devem sempre ser revistos e atualizados.

Andriguetto Filho (1999) propõe uma classificação da pesca para o litoral paranaense com base nas seguintes variáveis: demografia, caráter urbano ou rural, sistemas técnicos, comercialização e presença da agricultura. A análise feita pelo autor permite mostrar a complexidade da pesca de pequena escala, porém, também não permitiu realizar uma correspondência completa entre o sistema pesqueiro praticado em Bitupitá e os seis tipos de pesca descritos pelo autor. Para cada tipo de pesca 
descrito por Andriguetto Filho (1999) corresponde um mecanismo de divisão da produção. A partilha da produção entre vaqueiros, mata-vaqueiros, ajudantes e donos de currais é multímoda, ou seja, depende da posição do indivíduo, o que não foi contemplado pelo autor.

Constatamos, ainda, que a Política de Desenvolvimento da Pesca no Brasil (Lei $\mathrm{n}^{\circ}$ 11.959, de 29 de junho de 2009) está longe de abranger a realidade da pesca no Brasil, pois classifica essa atividade em apenas dois modelos estanques: o artesanal e o industrial. A divisão da pesca em duas categorias excludentes entre si indica que a legislação não levou em consideração a complexidade das relações de produção nem as leituras mais difundidas acerca do tema no Brasil. Essa constatação se deu a partir da observação participante, metodologia que permitiu uma imersão no cotidiano dos trabalhadores da pesca de curral em Bitupitá.

\section{Referências}

ANDRIGUETTO FILHO, J. M. Sistemas Técnicos de Pesca e suas Dinâmicas de Transformação no Litoral do Paraná. 1999. 242 f. Tese (Doutorado) - Programa de Pós-graduação em Meio Ambiente e Desenvolvimento, Universidade Federal do Paraná, Université Paris 7, Université Bordeaux 2, Curitiba, 1999 . Disponível em: < http://www.doutmeio.ufpr.br/teses/Jose_Milton_Andriguetto.pdf>.Acesso em: 28 nov. 2019.

ARAujO, A. G. P. ; RODRIGUES, L. C. Vaqueiros do Mar de Bitupitá, Ceará: a pesca de curral e os direitos de populações tradicionais. In: V Reunião Equatorial de Antropologia(REA) VIV Reunião de Antropólogos do Norte e Nordeste(ABANNE), 2015, Alagoas. Direitos diferenciados, conflitos e produção de conhecimento, 2015.

AZEVEDO, N. T. Política nacional para o setor pesqueiro no Brasil (2003-2011). 2012. 349 f. Tese (Doutorado) - Programa de Pós-graduação em Meio Ambiente e Desenvolvimento, Universidade Federal do Paraná, Curitiba, 2012. Disponível em: <http://hdl.handle.net/1884/29268>. Acesso em: 28 nov. 2019.

BRASIL. Decreto n. 6.040, de 7 de fevereiro de 2007. Institui a Política Nacional de Desenvolvimento Sustentável dos Povos e Comunidades Tradicionais. Diário Oficial da União de 08/02/2007, p. 316. Disponível em: < http:/www.planalto.gov.br/ccivil_03/_ato20072010/2007/decreto/d6040.htm>. Acesso em: 25 nov. 2019.

BRASIL. Lei n. 11.959, de 29 de junho de 2009. Dispõe sobre a Política Nacional de Desenvolvimento Sustentável da Aquicultura e da Pesca, regula as atividades pesqueiras, revoga a Lei no 7.679, de 23 de novembro de 1988, e dispositivos do Decreto-Lei no 221, de 28 de fevereiro de 1967, e dá outras providências. Diário Oficial da União de 30/06/2009, p. 1. Disponível em: < http://www.planalto.gov.br/ccivil_03/_ato2007-2010/2009/Lei/L11959.htm>. Acesso em: 17 jun. 2019. 
CARDOSO, E.S. Geografia e pesca: aportes para um modelo de gestão. Revista do Departamento de Geografia. São Paulo: USP, v. 14, p. 79-88, maio 2001. DOI: https://doi.org/10.7154/RDG.2001.0014.0008

CARTER, R. W. G. Coastal Environments: an introduction to the physical, ecological and cultural systems of coastlines. 8. ed. London: Academic Press, 2002.

DIEGUES, A. C. S. A pesca construindo sociedades: leituras em antropologia marítima e pesqueira. São Paulo: NUPAUB-USP, 2004.

DIEGUES, A. C. S. Pescadores, Camponeses e Trabalhadores do Mar. São Paulo: Ed. Ática, 1983.

FLICK, U. Introdução à pesquisa qualitativa. 3. ed. Porto Alegre, RS: Artmed, Bookman, 2009.

INSTITUTO BRASILEIRO DE GEOGRAFIA E ESTATÍSTICA. PANORAMA. Disponível em: $<$ https://cidades.ibge.gov.br/brasil/ce/barroquinha/panorama>. Acesso em: 15 jun. 2019.

MALDONADO, S. C. Pescadores do mar. São Paulo, SP: Ática, 1986.

MORAES, A. C. R. Contribuições para a gestão da zona costeira do Brasil: elementos para uma geografia do litoral brasileiro . 2. ed. ampl. São Paulo: Annablume, 2007.

MINAYO, M. C. S. Trabalho de campo: contexto de observação, interação e descoberta. In:

(Org.). Pesquisa social: teoria, método e criatividade. Petrópolis: Vozes, 2016. p. 56-71

PAIVA, M. P.; NOMURA, H. Sôbre a produção pesqueira de alguns currais-de-pesca do Ceará: dados de 1962 a 1964. Arquivos de Ciências do Mar, Fortaleza, v.5, n.2, p.175-214, dez.1965.

RODRIGUES, J. A. GIUDICE, D. S. A pesca marítima artesanal como principal atividade socioeconômica: o caso de conceição de vera cruz, BA. Cadernos do Logepa, v. 6, n. 2, p. 115-139, jul./dez. 2011.

TAMAR-ICMBIO. Levantamento das principais artes de pesca utilizadas nas comunidades pesqueiras na área de atuação do projeto TAMAR-ICMBIO. Itarema [?]: TAMAR-ICMBIO, 2013.

VERDEJO. M. E. Diagnóstico rural participativo: guia prático DRP. Brasília: MDA / Secretaria da Agricultura Familiar, 2010.

Artigo recebido em 08/09/2019. Aceito para publicação em 23/12/2019. 